\title{
Rescue management of recurrent duodenal and biliary obstruction due to lumen- apposing metal stent distal migration and duodenal stent ingrowth
}

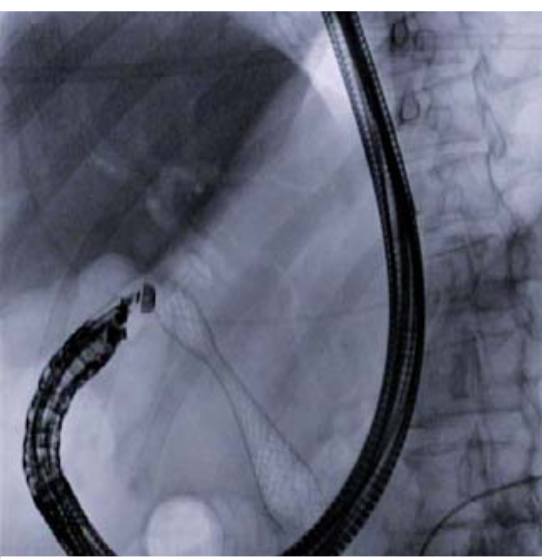

Fig. 1 Radiological view showing placement of the electrocautery-tipped lumenapposing metal stent (EC-LAMS) and duodenal self-expanding metal stent (SEMS).

Endoscopic palliation of concomitant biliary and duodenal malignant obstruction can be challenging because of difficult access to the papilla. Endoscopic ultrasound (EUS)-guided biliary drainage (EUS-BD) via a choledochoduodenostomy created using a lumen-apposing metal stent (LAMS) is an innovative and relatively new technique for palliation of distal biliary malignancy in patients with an unreacheable papilla [1-3].

We present the case of a 59-year-old woman with gastric outlet obstruction (GOO) and jaundice with an unresectable pancreatic cancer causing duodenal obstruction that had previously been treated with EUS-guided choledochoduodenostomy (EUS-CD) using an electrocautery-tipped LAMS (EC-LAMS; Hot Axios, $6 \times 8 \mathrm{~mm}$; Boston Scientific, Natick, Massachusetts, USA) and placement of a duodenal self-expanding metal stent (SEMS; WallFlex Duodenal, 22×60 mm; Boston Scientific) ( $>$ Fig. 1; $>$ Video 1 ).

The patient was readmitted 5 months after this procedure with fever and recurrence of her jaundice and GOO symptoms. Contrast-enhanced computed to-
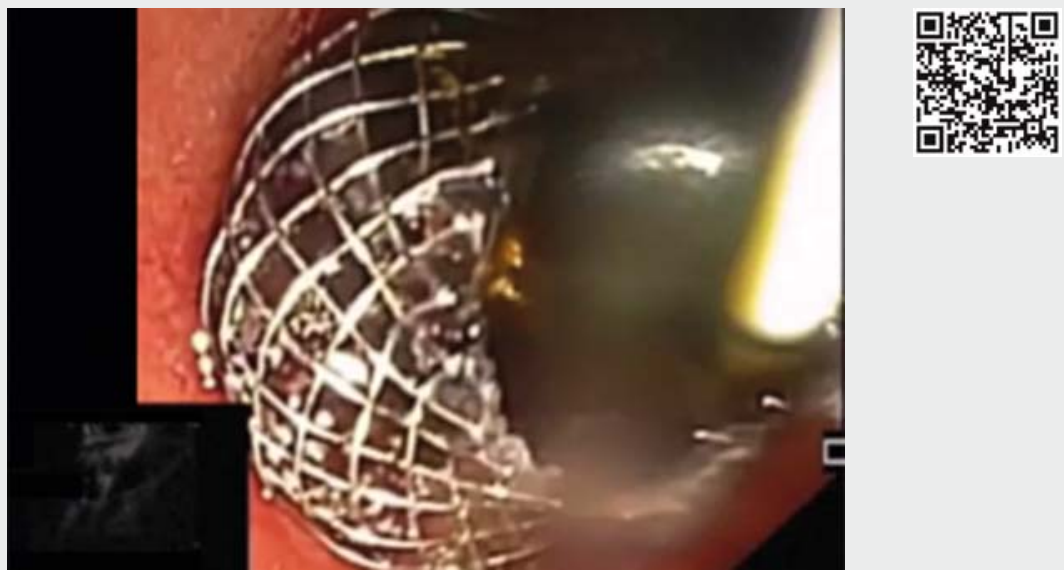

Video 1 An initially correctly placed lumen-apposing metal stent (LAMS) is subsequently shown to have migrated distally into the duodenal self-expanding metal stent (SEMS). After removal of the LAMS, a coaxial duodenal SEMS is placed, along with a plastic stent that is eventually replaced by a fully covered biliary SEMS passing through the duodenal stent mesh.

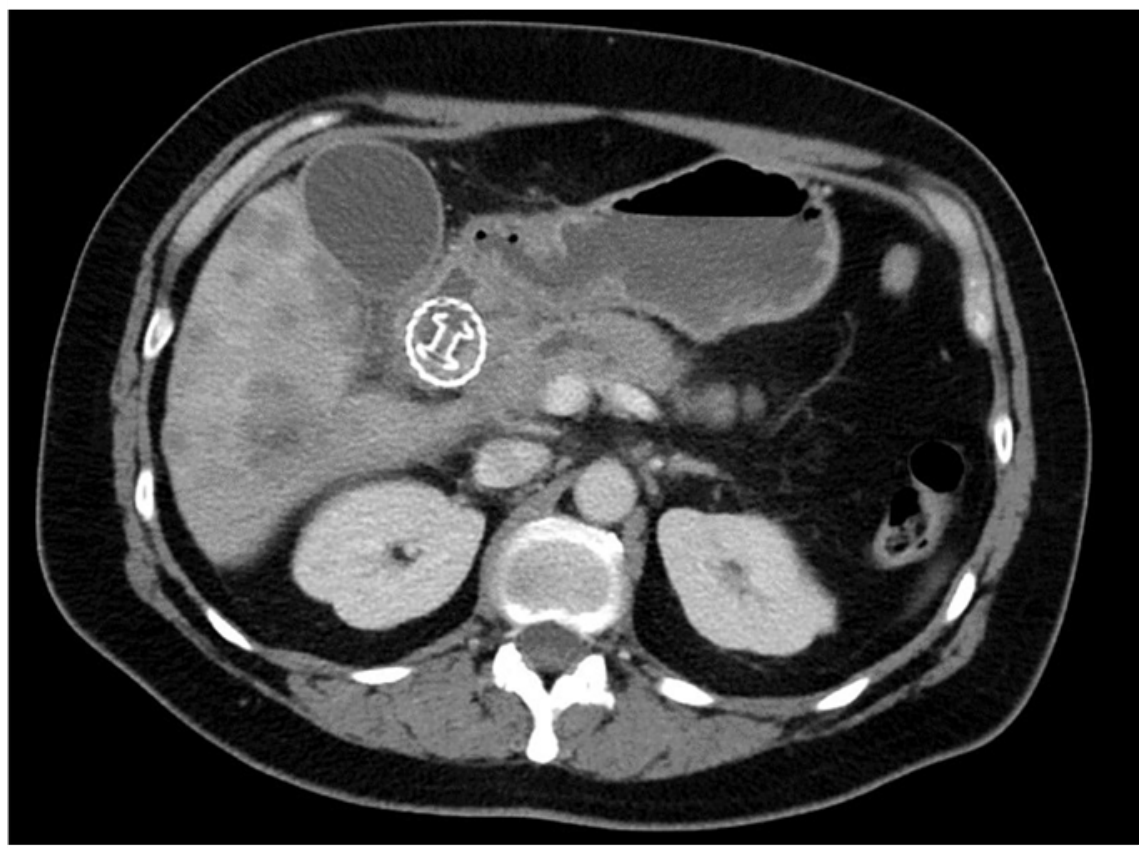

- Fig. 2 Contrast-enhanced computed tomography (CT) scan showing the electrocauterytipped lumen-apposing metal stent (EC-LAMS) that has migrated into the duodenal self-expanding metal stent (SEMS). 


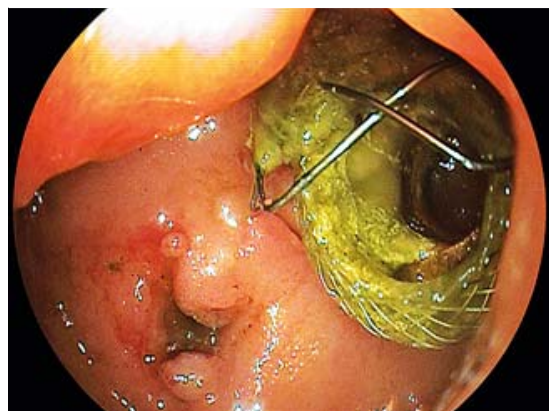

- Fig. 3 Endoscopic view of the electrocautery-tipped lumen-apposing metal stent (EC-LAMS) that has migrated into the duodenal self-expanding metal stent (SEMS) and the fistula that was left between the duodenum and the common bile duct (CBD).

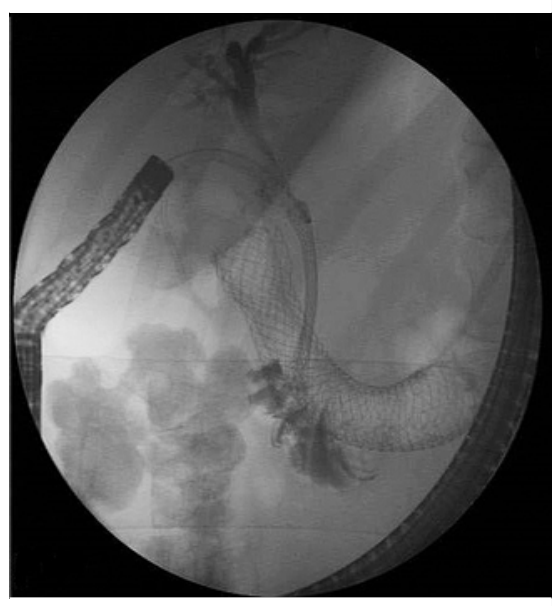

- Fig. 4 Radiological view of the two coaxial duodenal self-expanding metal stents (SEMSs) and the biliary self-expanding metal stent (SEMS) passing through the duodenal stent meshes.

mography (CT) scanning showed gastric distension, dilated intrahepatic biliary ducts, and biliary LAMS migration into the proximal flange of the duodenal stent ( $\triangleright$ Fig. 2).

After the LAMS had been removed endoscopically ( $\sim$ Fig. 3 ), the common bile duct (CBD) was cannulated in antegrade fashion through the transbulbar fistula and a double-pigtailed plastic stent $(7 \mathrm{Fr} \times 5 \mathrm{~cm})$ was placed into the CBD. A duodenal SEMS was then placed coaxially to the previous one to guarantee duodenal stent patency. After 15 days, duodenal stent patency was confirmed and the biliary plastic stent was replaced with a fully covered SEMS $(40 \times 10 \mathrm{~mm})$, with the distal flange passing through the duodenal stents mesh ( $\triangleright$ Fig.4). No further recurrence occurred during follow-up.

Our report suggests that the presence of a choledochoduodenostomy allows for successful endoscopic management of concomitant biliary and duodenal malignant obstruction, with effective biliary drainage being achieved.

Endoscopy_UCTN_Code_CPL_1AL_2AD

Competing interests

None

The authors

Simona Attardo ${ }^{1}$, Francesco Auriemma ${ }^{1}$, Alessandro Fugazza', Roberta Maselli ${ }^{1}$, Silvia Carrara ${ }^{1}$, Andrea Anderloni ${ }^{1}$, Alessandro Repici $^{1,2}$

1 Humanitas Clinical and Research Center, Digestive Endoscopy Unit, Division of Gastroenterology, Rozzano, Milano, Italy

2 Humanitas University, Department of Biomedical Sciences, Rozzano, Milano, Italy

\section{Corresponding author}

Simona Attardo, MD

Digestive Endoscopy Unit, Via Manzoni 56, 20089 Rozzano, Milano, Italy

Fax: +39-02-82244590

simona.attardo12@gmail.com

\section{References}

[1] Anderloni A, Buda A, Carrara S et al. Singlesession double-stent placement in concomitant malignant biliary and duodenal obstruction with a cautery-tipped lumen apposing metal stent. Endoscopy 2016; 48 (Suppl. 01): E321-E322

[2] Jain D, Shah M, Patel U et al. Endoscopic ultrasound guided choledocho-enterostomy by using lumen apposing metal stent in patients with failed endoscopic retrograde cholangiopancreatography: a literature review. Digestion 2018; 98: 1-10

[3] Anderloni A, Fugazza A, Troncone E et al. Single-stage EUS-guided choledochoduodenostomy using a lumen-apposing metal stent for malignant distal biliary obstruction. Gastrointest Endosc. doi:10.1016/j. gie.2018.08.047

\section{Bibliography}

DOI https://doi.org/10.1055/a-0836-2447

Published online: 5.3.2019

Endoscopy 2019; 51: E118-E119

(c) Georg Thieme Verlag KG

Stuttgart · New York

ISSN 0013-726X

\section{ENDOSCOPY E-VIDEOS}

https://eref.thieme.de/e-videos

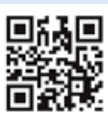

Endoscopy E-Videos is a free access online section, reporting on interesting cases and new

techniques in gastroenterological endoscopy. All papers include a high quality video and all contributions are freely accessible online.

This section has its own submission website at https://mc.manuscriptcentral.com/e-videos 